\title{
The Acquisition of French (L3) Wh-question by Persian (L1) Learners of English (L2) as a Foreign Language: Optimality Theory
}

\author{
Azam Mollaie ${ }^{1}$, Ali Akbar Jabbari ${ }^{1} \&$ Mohammad Javad Rezaie ${ }^{1}$ \\ ${ }^{1}$ College of English Literature, Yazd University, Yazd, Iran \\ Correspondence: Azam Mollaie, College of English Literature, Yazd University, Yazd, Iran. Tel: \\ 98-917-878-6390. E-mail: a.mollaie.6655@gmail.com
}

Received: July 2, 2016 Accepted: November 6, 2016 Online Published: December 1, 2016

doi:10.5539/ijel.v6n7p36 URL: http://dx.doi.org/10.5539/ijel.v6n7p36

\begin{abstract}
Recent decade has been prominent in investigating third language acquisition (L3). This study presents an Optimality theoretic account of French wh-question by learners whose first and second language are Persian and English respectively. Additionally, it investigates transfer at the initial stage based on the three dominant transfer hypotheses namely, L1 transfer hypothesis, L2 status factor, Cumulative Enhancement Model (CEM) in the domain of L3 acquisition. First, in French and Persian wh- question structure, the wh-word move to pre subject position (Spec-CP \& Spec-FOCP) but the interrogative verb do not raise to C. This is the indicator of L1 Factor hypothesis. Second, in French and English the wh-word follows by an interrogative verb in French or by subject-auxiliary inversion in English so in these languages the wh-word occupies the Spec-CP and the verb occupies the C position. This is an evidence for L2 status factor. Third, in English and Persian the wh-word remains in original position for echo questions, this feature triggers this parallel structure in French; this confirms Cumulative Enhancement Model hypothesis. Two groups of Persian native speakers with different English proficiency levels (the lower-intermediate \& advanced) that were at the initial stage of acquiring L3 French were asked to complete two test namely, grammar judgment task and translation test. The results showed that the main source of transfer was L1 transfer hypothesis and partially CEM. Regarding OT, although the advanced learners transferred their L2 knowledge in the L3 acquisition in GJT, there was not any significant difference between L1 transfer and L2 transfer context. Therefore, the following constraint hierarchies were obtained for TT and GJT respectively, Q-Scope $>>$ Lex-V $>$ Stay $>>$ Q-Mark and Stay $>>$ Lex-V $>>$ Q-Mark $>>$ Q-Scope. In fact, these ranking, particularly the former one, advocated the L1 transfer hypothesis.
\end{abstract}

Keywords: Cumulative Enhancement Model hypothesis, L3 acquisition, L2 status factor, L1 transfer hypothesis, optimality theory, wh-question

\section{Introduction}

During the last decade, third language acquisition (TLA) has developed as another field to focus on the transfer of L1 and L2 to L3 (Cenoz, Hufeisen, \& Jessener 2001; Clyne, Hunt, \& Isaakidis, 2004; Ringbom, 2007; Rothman, 2011). One of the main issues in this field is the topic of crosslinguistic influence (CLI). TLA research studies crosslinguistic influences with the purpose of identifying the underlying principles that might determine the learner's preferences at a given time for utilizing an element crosslinguistically.

These studies have determined that there is a difference between L2 and L3/Ln acquisition. The method for distinguishing L3 acquisition from L2 acquisition is diverse and complex. It has been pointed out by many that the acquisition of a true L2 and an L3 is not the same. A significant factor is the plurality of possible interactions between the linguistic systems in the multilingual learner's mind. Second language learners have two frameworks that can independently impact each other $(\mathrm{L} 1 \rightarrow \mathrm{L} 2)$. Two other bidirectional relationships can occur in third language acquisition: the L3 can impact the L1 and be affected by the L1 (L1 $\rightarrow \mathrm{L} 3)$ and cross-linguistic influence can also occur between the L2 and the L3 (L2 $\rightarrow$ L3) (Cenoz, Hufeisen, \& Jessner, 2001).

The L3 acquisition of wh-questions has broadly been examined by researchers. All languages have distinctive procedures or strategies which enable speakers to ask wh-constituents, but these strategies vary cross-linguistically. With respect to experimental evidence all languages are distinct on the surface. For instance, there are languages which move question words to the sentence's front and languages which allow question 
words to remain in original situation or inside the sentence. In this regard, there are many theories that analyze the structure of wh-questions. For example, with respect to previous theories such as minimalism program (MP), principles of UG are both universal and inviolable. But according to Optimality Theory (OT; Prince \& Smolensky, 1993), principles of UG are universal but violable.

This study proposed to combine a few bits of knowledge to the recently investigated field of third language acquisition. To this end, it researched the acquisition of French (L3) simple wh-questions by Persian learners concerning L1 Transfer Hypothesis, L2 Status Factor Hypothesis, and Cumulative Enhancement Model. With respect to the optimality theory, this study analyzes the structure of wh-question of three languages under study (Persian, English, and French).

This study tested the three transfer hypotheses namely, L1 transfer hypothesis, L2 status factor, and CEM. The findings of this study could support these hypotheses. Therefore, the findings of this study can help multilingualism and provide more insights in language acquisition specially the L3. The present study has provided empirical data which contribute to the development of interlangauge theories.

Multilingualism is a growing concern globally and particularly in Iran. In this regard, studying the factors affecting L3 is of great importance in such contexts. Pedagogically, the findings of the study can be helpful for teachers, students, material developers and course designers who are concerned with learning and teaching of third language. The results of this study will help teachers to know the main area of difficulty in the acquisition of French wh-question constructions by Persian learners.

Bilingual and multilingual individuals represent a various type of linguistic competence as contrasted with that of monolinguals (Grosjean, 1989; Cook, 1995; Jessner, 1999). A great part of the present study recommends that learning a third language is not the same as learning a second one (Jessner, 1999; Cook, 1995). Herdina \& Jessner (2002) stated that acquiring more than two language systems leads to the development of new skills such as learning how to learn; moreover it facilitates subsequent additional language acquisition as learners utilize metalinguistic awareness to investigate the cognitive and linguistic mechanisms underlying language.

\section{Material Studied}

The acquisition of L3 contrasts sharply with the acquisition of L2. The only source of transfer in L2 is the native language of the learners, while in L3 there is more than one source of transfer. In this regard, transfer may occur either from the learners' L1 or L2 or both. Due to this complex situation in crosslinguistic (CLI) studies, researchers have proposed various hypotheses regarding the source of transfer. There are three hypotheses that are of utmost importance in the field of L3 acquisition. These are "L1 Factor" Hypothesis (Hakanssson et al., 2002), the "L2 Status factor" Hypothesis (Bardel \& Falk, 2007) and the CEM (Flynn et al., 2004; Flynn, 2009) suggests that all the previously learned languages can be transferred into the $\mathrm{L} n$. The $\mathrm{L} 1$ or the mother tongue acts as a default language; that is, it is transferred into the $\mathrm{L} 3$ if it is available in the $\mathrm{L} 1$, and in case the structure is not present in the L1, then they transfer from the other languages.

According to Bardel \& Falk (2011), "The L2 status factor hypothesis implies that the L2 can supersede the L1 as a source of transfer, because of a higher degree of cognitive similarity between L2 and L3, than between L1 and L3" (p. 61). The L2 status factor has its origin in Williams \& Hammarberg's study on L3 acquisition of the lexicon (1998) where it was explained as a general tendency to activate a previously learned (second) language, rather than to activate the L1 in the acquisition of a third one. Bardel \& Falk (2007) found in their first study that the same holds for the acquisition of L3 syntax.

Finally, L1 Factor Hypothesis is one of the most considerable L3 acquisitions hypotheses in the studies of CLI introduced by Hakansson et al. (2002). This hypothesis claims that native language is the primary source of transfer at the initial state of L3 acquisition. Some recent studies on L3 acquisition suggest that transfer occurs from L1 (Leung, 2005 a \& b).Contrary to the findings of Jorge Pinto (2013) and Bardel \& Falk, in this paper, we will demonstrate that there is no impeding role for the L2 in the L3 acquisition, and the L1 plays a significant role in acquiring the L3, which is in line with the FT/FA Model.

\subsection{Optimality Theory}

In Optimality Theory (Prince \& Smolensky, 1993; Grimshaw, 1995; Kager, 1999) Universal Grammar consists of a set of soft (violable) constraints on well-formedness and individual grammars are constructed by the reranking of these constraints. The expression that satisfies the higher ranked constraints is the optimal, thus, the grammatical one; the others are then considered ungrammatical. The OT architecture contains an Input that consists of elements from the lexicon. A general structure generator (Gen) constructs candidate expressions from the Input that constitute the candidate set. In the evaluation part, the optimal candidate is selected, based on the 
language-specific constraint-hierarchy.

The most important issue in OT interrogative investigation is the constraints which determine the position of the wh-phrase, whether in a fronted position or in-situ. The competing constraints in this position as originally formulated by Grimshaw (1997) are STAY (trace is not allowed) and OP-SPEC (syntactic operators must be in specifier position). The former discourages wh-movement whereas the latter encourages it.

Operator-In-Specifier (OP-SPEC): Syntactic operators must be in specifier position (Grimshaw, 1995, 1997).

STAY: Trace is not allowed (Grimshaw, 1997).

1) What will robin eat?

Table 1. Ranking argument: OP-SPEC > STAY (McCarthy, 2008)

\begin{tabular}{lll}
\hline & Op- Spec & Stay \\
\hline a. $\rightarrow$ [CP What will [IP Robin [VP eat ]]] & & $* *$ \\
b. [IP Robin will [VP eat what]] & $* !$ & \\
\hline
\end{tabular}

What comes next is the concept that every maximal projection must have a head, the constraint for that is called Obligatory- Heads or OBHD.

Obligatory- Heads (OB-HD): A projection has a head limitation is a lethal one (Grimshaw, 1997).

Since wh-movement is constantly joined by movement of the auxiliary from I to C, then OB-HD must dominate STAY. The sample to demonstrate this dominance relation is one where OB-HD is satisfied and STAY is violated and the clause retains its grammaticality. The ungrammatical illustration (the loser) that compete with it ought to be one where OB-HD is violated but the constraint OP-SPEC must not be violated as it is demonstrated in previous ranking argument that it dominates Stay.

Table 2. Ranking argument: OB-HD > STAY (McCarthy, 2008)

\begin{tabular}{|c|c|c|c|}
\hline & OB-HD & OP-Spec & stay \\
\hline a. $\rightarrow$ [CP What will [IP Robin [VP eat ]]] & & & $* *$ \\
\hline b. [CP What_[IP Robin will [VP eat ]]] & *! & & * \\
\hline
\end{tabular}

The optimal form (a) satisfies the OB-HD constraint by moving the auxiliary (will) to C. The ranking between OB-HD and OP-SPEC is still undetermined. The OT explanation of an element that is needed to satisfy a high ranking constraint is that this element must violate another constraint that forbids its presence. The later constraint in the case of English Do- Support is Full- Interpretation or FULL-INT:

Full-Interpretation (FULL-INT): Lexical conceptual structure is parsed (Grimshaw, 1997).

This constraint is violated by the presence of any element that is not present in the input. The winner contains Do which incurs a violation of STAY:

2) [CP what did [IP Robin [VP eat]]]

The loser should be one where it does not have Do, thus OB-HD is violated. However, STAY is only violated once since there is no Do to move:

Table 3. Ranking argument: OB-HD >> FULL-INT >> STAY (McCarthy, 2008)

\begin{tabular}{llll}
\hline & OB-HD & Full-Int & Stay \\
\hline a. $\rightarrow[$ CP What did [IP Robin [VP eat $]]]$ & & $*$ & $* *$ \\
b. [CP What_[IP Robin_[VP eat $]]]$ & $* *$ & & $*$ \\
\hline
\end{tabular}

This example demonstrates that to fulfill a higher-ranking constraint, a lower ranked one could be violated even by the winner. In this situation, FULL-INT is violated once and STAY is violated twice. The violations brought about by the loser are lethal. The ranking between FULL-INT and STAY is yet to be determined. The other constraints to explain interrogatives are defined as follows:

Q-Marking: a question must be overtly Q-marked where marking requires VP to be the complement of the 
Q-marker (Ackema \& Neeleman, 1995, 1998).

Q-Scope: [+Q] elements must c-command VP at surface structure (Ackema \& Neeleman, 1995, 1998).

It will be clear that there is some overlap in the empirical effects of Q-Marking and Q-Scope. Both principles may trigger wh-movement. There are constructions in which one is crucially satisfied, while the other is not. For example, movement of a wh-expression without accompanying head movement will result in a structure that violates Q-Marking, but satisfies Q-Scope. Moreover, partial overlap in the effects of conditions is not to be regarded as a conceptual disadvantage.

Table 4. Ranking argument: Q-Marking $>$ Q-Scope> Stay

\begin{tabular}{llll}
\hline & Q-Marking & Q-Scope & Stay \\
\hline$\rightarrow$ a. [CP what have [IP you [vP seen?]] & & & $* *$ \\
b. [IP You [vp have seen what?]] & $* !$ & $*$ & $*$ \\
c. [CP What [IP you [vp have seen?]] & $* !$ & & $*$ \\
d. [CP Have [IP you [VP Seen what?]] & $* !$ & $*$ & \\
\hline
\end{tabular}

The optimal candidate is a. All other candidates fatally violate Q-Marking. The second one, this is immediately clear, since nothing has been moved. The third one, what has been adjoined to VP (thus complying with Q-Scope), but an adjunction structure is not a proper structure for marking (only a head-complement structure). The last candidate fatally violates the highest ranking constraint by not moving the wh-word to Spec-C. According to these constraints that are used in wh-question constructions, the general ranking of these constraints are defined as follows:

Q-Mark $>>$ OP-Spec $>>$ Q-Scope $>>$ Obligatory-Head $>>$ Full-INT $>>$ Stay

Based on the theoretical framework of the study, four research questions were raised in line with the objectives of the present study:

1) What is the role of L1 Transfer Hypothesis in the acquisition of French simple wh-questions?

2) What is the role of L2 Status Factor in the acquisition of French simple wh-questions?

3) What is the role of Cumulative Enhancement Model in the acquisition of French simple wh-questions?

4) How does Optimality Theory account for the acquisition of simple French wh-questions?

\section{Area Description}

Recent studies in comparative syntax attempt to provide clarifications for cross-linguistic variety in the declaration of a similar phenomenon, that is to say, the nature of wh-questions in distinctive languages. Despite the fact that there have been a vast number of studies researching the obtaining of wh-questions by L1 and L2 speakers, almost no work has been done on the issue of L3 acquisition of wh-questions with the optimality theory account.

\subsection{Persian Wh-question Structure}

According to the various proposals pertaining to the issue of wh-movement in Persian, it is proposed that Persian is a wh-in situ language in the way that the wh-words stay in their original positions. Concerning the basic word order, Persian is an SOV language, with fairly free word order, which does not exhibit obligatory single wh-movement comparable to English (Karimi, 2003). Due to the presence of wh-particle in Persian, the Q feature is checked via the wh-particle and there would be no requirements for the wh-words to rise into the Spec of $\mathrm{CP}$ for the checking purposes. The other form of Persian wh-question is wh-fronting. However, this movement differs from English syntactic wh-movement which is the movement of a wh-phrase to Spec-CP and types a clause as a wh-question. However, the fronting of wh-phrases in Persian is analyzed as focus movement (Kahnemuipour, 2001). In Persian [+wh] feature is always weak, so Persian must be triggered by an optionally realized strong [+focus] feature. Thus, it is suggested that the strong [+focus] feature is realized in Foc position in Persian, and that Focp is generated below CP and above TP (Kahnemuypour, 2001). If the strong [+focus] feature is not selected, we get wh-in situ. The following examples show the structure of Persian wh-questions:

3) a. uo che-chizi kharid

b. she what buy

c. what did she buy? 
Table 5. Ranking argument of Persian wh- in situ question

\begin{tabular}{|c|c|c|c|}
\hline & Stay & Lex-V & Op-spec \\
\hline$\rightarrow$ a. [FOC.P + Q[IP uo [vp che chizi kharid]]] & & & $*$ \\
\hline b. [Foc-P che chizi [IPuo [vp kharid]]] & $* !$ & & \\
\hline c. [FOC-P kharid [IPUo [vp che-chizi]]] & $*$ & $* !$ & $*$ \\
\hline d. [FoC-P che chizi kharid [IPUo [vP-]]] & $* * !$ & & \\
\hline
\end{tabular}

Lexical verb (Lex-V): lexical verbs cannot Q-mark a question.

The optimal form is candidate a. It satisfies the highest-ranked constraint Stay by not moving the wh-word to the highest position (Spec-Focp). Also, it satisfies the second constraint Lex-V by not moving the lexical verb to Spec-Focp. Finally, it violates the lowest-ranked constraint OP-Spec by not moving the operator (wh-word) to Spec-Focp position. Since it is the lowest-ranked constraint, its violation is not fatal. Candidate $b$ fatally violates the highest-ranked constraint by moving the wh-word to presubject position. Candidate $\mathrm{c}$ fatally violates the second constraint Lex-V by moving the lexical-verb to Spec-Focp. Furthermore, candidate d fatally violates the highest-ranked constraint twice by moving the wh-word to Spec-focp and moving the interrogative verb to the head of focp.

4) a. koja uo raft?

b. Where she went

c. Where did she go?

Table 6. Ranking argument of Persian wh-fronting

\begin{tabular}{|c|c|c|c|}
\hline & OP-Spec & Lex- V & Stay \\
\hline$\rightarrow$ a. [FOC-P koja[IP uo [vP raft]]] & & & $*$ \\
\hline b. [FOC-P koja raft [IP uo[vP-]]] & & & $* * !$ \\
\hline c. [FoC-P raft [IP Uo[vP koja]]] & $* !$ & $*$ & $*$ \\
\hline d. [CP $+Q[$ IP uo [vP koja raft]]] & $* !$ & & \\
\hline e. [CP raft koja[ IP uo[vP-]]] & $* !$ & $*$ & $* *$ \\
\hline
\end{tabular}

Candidate is the optimal form. It satisfies the highest-ranked constraints by moving the wh-word to Spec-Focp position. Candidate $b$ fatally violates stay twice by moving the wh-word as well as the lexical verb to presubject position. Candidate $\mathrm{c}, \mathrm{d}$ and e fatally violate the highest-ranked constraint by not moving the operator to Spec-Focp position.

\subsection{English Wh-question Structure}

Chomsky (1995) argues that question formation results from the syntactic presence in C-position of a strong question affix, [Q]. for Chomsky, Q is a "strong affix", strong features must be checked by PF (Phonetic Form), and thus Q requires an overt head, realized by Subject-Auxiliary Inversion (SAI) (Radford, 1997, p. 247). Furthermore, Q has a strong [+wh] specifier feature which must be checked via specifier-head agreement through the movement of a wh-operator to Spec-CP (Radford, 1997, pp. 271-274).

Following Chomsky (1995) and Radford (1997), in English, interrogative clauses are CPs headed by a strong C which contains the strong question affix [Q]. The strong $\mathrm{Q}$ affix needs an overt head to attach to it. The shortest movement principle requires that this head must be the auxiliary in I. That is, auxiliary moves from the head I position in IP into the Head C position in CP. Since Q also carries a [wh] specifier-feature, the wh-operators move to Spec-CP in order to check the interrogative specifier-feature carried by Q. Thus, the two properties of [Q] in English demand two types of movements: head movement to $\mathrm{C}$ position and operator movement to Spec-CP position. What will they read?

Table 7. Ranking argument of English argument wh-question

\begin{tabular}{llll}
\hline & Op-Spec & Ident (Tns) & Stay \\
\hline a. [IP they will [VP read what]] & $* !$ & & \\
b. [CP [IP they will [VP read what]]] & $* !$ & $*$ & $*$ \\
c. [CP what [IP they will [VP read]]] & & $* !$ & $* *$ \\
d. [CP what will [IP they [VP read]]] & $* !$ & & $*$ \\
e. [CP will [IP they[VP read what]] & $* !$ & & \\
\hline
\end{tabular}


Before describing the example, we consider markedness constraint utilized in the present analysis:

IDENT (TNS): The Tense identity of C must be preserved (McCarthy, 2008)

Candidate a fatally violates OP-Spec by not moving the wh- word to the Spec position. Candidate $\mathrm{b}$ fatally violates OP-Spec and also Ident (Tens) the latter by not moving the auxiliary from I to C. Candidate c violates Ident (Tens), $\mathrm{C}$ of the $\mathrm{CP}$ is empty. Candidate $\mathrm{d}$ is the winner. It satisfies both the higher- ranked constraints with the wh-word's movement to the Spec position and C is filled. The optimal form violates Stay twice, but since this constraint is low-ranked, its violations do not have any impact on the outcome of the competition. Candidate e violates OP-Spec and Stay.

The dummy Do occurs in interrogatives only when it is required. The faithfulness constraint that monitors every component in the Input and makes sure that it is present in the output is Full-Int:

FULL-INT (Full Interpretation): lexical conceptual structure is parsed (Grimshaw, 1997).

This constraint also has the job of determining any component in the output that has no content. Do here is not the lexical verb that indicates performing an action, rather it is treated as a place holder for Tense:

5) What did she say?

Table 8. Ranking argument of English wh-question with auxiliary (did)

\begin{tabular}{|c|c|c|c|c|c|}
\hline & Op-Spec & No-Lex-Mvt & Ident-(Tns) & Full-Int & Stay \\
\hline$\rightarrow$ a. [CP what did [IP she [VP say]]] & & & & $*$ & $* *$ \\
\hline b. [CP what [IP she [VP said]]] & & & $* !$ & & $*$ \\
\hline c. [CP what [IP she did[VP say ]]] & & & $* !$ & $*$ & $*$ \\
\hline d. [CP what said [IP she [VP]]] & & $* !$ & & & $* *$ \\
\hline
\end{tabular}

The winner is candidate a; it satisfies the higher- ranked constraints OP-Spec by moving the wh- word to a Spec position and Ident (Tens) by moving the head from I to C. This optimal form violates Full-Int by inserting an auxiliary verb that is not present in the input. The winner violates Stay twice. Candidate $b$ violates Ident (Tens) and Stay. Candidate c violates Ident (Tens), Full-Int, and Stay. Candidate d violates No-Lex-Movement by moving the lexical verb from $\mathrm{V}$ to I; this movement is prohibited in English. To keep from having such candidates as winners, a constraint is introduced that keeps lexical heads from moving:

NO-LEX-MVT (No Lexical Movement): A lexical head cannot move (Grimshaw, 1997).

\subsection{French Wh-question Structure}

One of the most interesting features of French Wh-questions is the fact that they take into account an extensive variety regarding the constructions used and, more particularly, regarding the movement operations within those constructions. In particular, while many languages have an obligatory rule for the derivation of a wh-question (e.g., move wh-element to spec-CP, invert the auxiliary and the subject, etc.), French allows wh-questions to be determined via what seems to be an optional rule (i.e., the wh element can be moved to spec-CP or remain in its base position, the auxiliary/verb can move to a pre-subject position, or remain in a post-subject position).

Table 9. Types of wh-question constructions in French

\begin{tabular}{|c|c|c|c|}
\hline \multicolumn{2}{|l|}{ WH-construction } & \multirow{2}{*}{$\frac{\text { register }}{\text { Informal }}$} & \multirow{2}{*}{ Examples } \\
\hline 1. Wh-in situ & S-V-WH & & \\
\hline 2. Wh fronting without inversion & WH-S-V & Informal & $\begin{array}{l}\text { You live where? } \\
\text { Ou tu habites }\end{array}$ \\
\hline & & & Where you live? \\
\hline 3. Wh-fronting with inversion & Wh-V-S & Formal & $\begin{array}{l}\text { Ou habites- tu? } \\
\text { W here live you? }\end{array}$ \\
\hline 4. $\mathrm{Wh}+$ est-ceque & WH-estceque-S-V & Neutral & $\begin{array}{l}\text { Ouest-ce que tu habites? } \\
\text { Where do you live? }\end{array}$ \\
\hline
\end{tabular}

6) a. Vous faiths quoi?

b. You do what

c. What are you doing? 
Table 10. Ranking argument of French argument wh-in-situ question

\begin{tabular}{|c|c|c|c|c|}
\hline & STAY & LEX-V & Q-MARK & Q-SCOPE \\
\hline$\rightarrow$ a. [cp $+Q[$ ip Vous[vp faith quoi]]] & & & $*$ & $*$ \\
\hline b. [CP+ $\mathrm{Q}_{\mathrm{c}}$ Que[ [IP Vous[ [vP faites]]] & $* !$ & & $*$ & \\
\hline c. [cp Fait-[ip vous [ [vp quoi]]] & $*$ & $* !$ & $*$ & $*$ \\
\hline d. [cp Que ${ }_{c}$ faites[ip-vous[vp-] & $* * !$ & & & \\
\hline
\end{tabular}

7) a. Ou vous-habites?

b. Wher you live

c. Where do you live?

Table 11. Ranking argument of French adjunct wh-fronting without movement I to C

\begin{tabular}{lllll}
\hline & Q-Scope & Lex-V & Stay & Stay \\
\hline$\rightarrow$ a. $[\mathrm{CP}$ Ou[IP Vous[vp habites]]] & & & $*$ & $*$ \\
b. $[\mathrm{CP}$ habites Ou [IPVous[vP]]] & $* !$ & $*$ & $* *$ & $*$ \\
c. $[\mathrm{CP}$ Habite-[IPVous [Vp Ou]]] & $* !$ & $*$ & $*$ & $*$ \\
d. $\left[\mathrm{CP}+\mathrm{Q}\left[{ }_{\mathrm{IP}}\right.\right.$ Vous[VP-habites ou]]] & $* !$ & & & $*$ \\
e. $[\mathrm{CP}$ Ou habites [IPVou[VP-]]] & & & $* * !$ & \\
\hline
\end{tabular}

Candidate is the optimal form. It satisfies the highest-ranked constraint Q-Scope by moving the wh-word to Spec-C position. Candidate $b, c$, and d violate the highest-ranked constraint so they can not be a treatment to the optimal form. Candidate e fatally violates Stay by moving the lexical verb from VP to CP.

\section{Method}

\subsection{Participant Characteristics}

The participants of this study were 60 native speakers of Persian with English as their L2 and French as their L3. They were randomly selected from a population of Iran language institute in Shiraz which constituted elementary L3 learners with different L2 proficiency levels. Since the aim of study was to investigate the L3 acquisition of simple wh-question formations, the French level of the participants was determined to be beginner.

\subsection{Sampling Procedure}

After administering the English Oxford placement test, the participants were divided into two groups, each group involved thirty participants, one of the groups was lower-intermediate and the other one was advanced learners. Then they were given French one to ensure all of the learners had similar levels of proficiency in L3. Furthermore, there were two types of experiments: a grammaticality judgment test (GJT) and a translation test (TT).

\subsubsection{Grammar Judgment Test}

This type of test was used to test the comprehension ability and the competence of the learners. The test consisted of 16 items, each followed by three options of grammatical, ungrammatical, and I don't know, written in French and the students had to judge the grammaticality of each sentence. Among these items, there were 4 distracters irrelevant to wh-question, and the rest of the items were all representative of wh-question formation in French. The whole items were constructed on the basis of the three scenarios of the research. The first scenario conformed to L1 Factor hypothesis consisting of 4 items; the second scenario was related to L2 Status Factor containing of 4 items; and the third scenario was Cumulative Enhancement Model consisting of 4 items.

\subsubsection{Translation Test}

This kind of task has special impact because it helps us to better understand the influence of background languages. In other words, the language learners were exposed to the written sentences in the first and second languages i.e., Persian and English respectively. The test was in the written form and contained 14 items in learners' first and second languages. The items from 1 to 7 were in Persian and those from 8-14 were in English. Since the learners might have produced different types of French interrogative, each question was coded with 5 values as follows.

1) Correct wh-in-situ

2) Correct move without movement from I to $C$ position 
3) Correct move with movement from I to $\mathrm{C}$ position

4) Correct move with est-ceque

5) Wrong

\section{Results}

As noted earlier in previous section. This research study was an attempt to investigate the acquisition of simple French wh-question concerning OT by the two groups of learners with different English (L2) proficiency levels. To arrive at possible answers to the research questions, the results of the GJT and the TT are given in turn.

\subsection{Statistics and Data Analysis}

The following figure represents the impact of the contexts on the two groups.

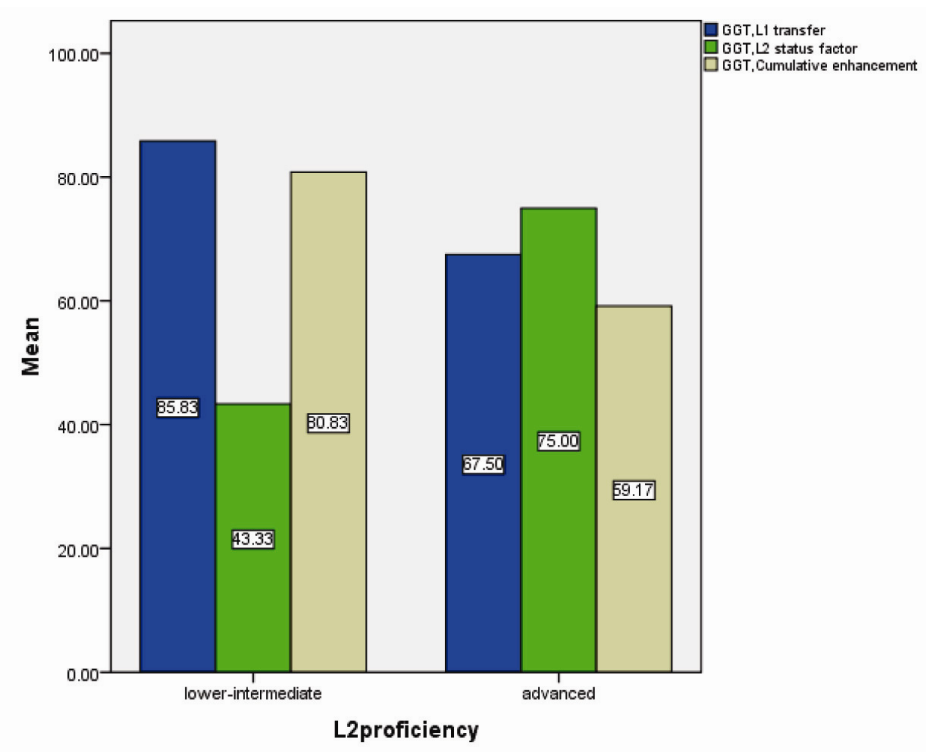

Figure 1. Participants' performance in GJT

As it can be inferred, the lower-intermediate group outperformed the advanced one in the first context (L1 transfer). Nevertheless, the mean scores of the two groups were high in this context and it could be assumed that both groups transferred the Wh-question structures from L1 to L3. In the second context, the advanced learners tended to transfer the wh-question structures from their L2 to L3. However, the mean score of this context (L2 status factor) was low compared to the other contexts. In this regard, L2 proficiency level had a reverse role and there was a significant difference between the mean score of the two groups in these contexts. Nevertheless, the men score of the two groups were high in the first context and it could be assumed that both groups transferred the wh-question structure from L1 to L3. However these differences are supported by the results of Two-way ANOVA.

Table 12. Mixed ANOVA results of GJT

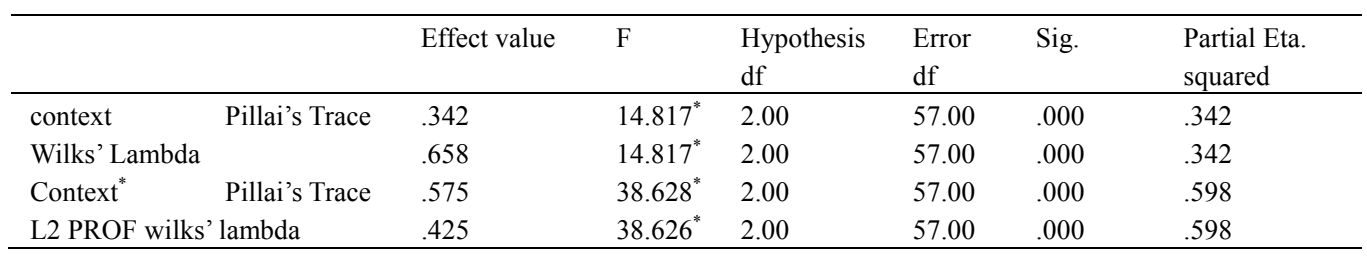

The effect of the three contexts was significant. The pairwise comparison table showed where this difference lied. Furthermore, the result presented that there was an interaction effect between the two groups with the contexts (i.e., L1 transfer, L2 transfer, \& CEM) [wilks' Lambada $=0.40, \mathrm{~F}(2,57)=42.46, p=0.000$ ]. The partial eta squared 0.59 showed a large effect size. So the performance of the students with the two different levels of 
English proficiency differed in the three contexts. In this regard a one way repeated measure ANOVA was conducted to see where this difference lied. According to these findings, L1 (Persian) was the main source of transfer for both groups. Although the advanced group got the higher mean score in L2 status factor context, the pairwise comparison of advanced group showed that there was not a significant difference between L1 transfer and L2 transfer contexts.

Table 13. Pairwise comparison of contexts

\begin{tabular}{lllllll}
\hline & & & & & \multicolumn{2}{c}{$\begin{array}{c}\text { 95\%confidence interval for } \\
\text { Difference }^{\mathrm{a}}\end{array}$} \\
\cline { 5 - 7 } context & context & Mean difference(I-J) & Std. Error & Sig. & Lower Bound & Upper bound \\
\hline L1 transfer & L2transfer & 17.500 & 3.353 & .000 & 9.233 & 23.767 \\
L1 transfer & CEM & 6.667 & 4.352 & .393 & -4.063 & 17.397 \\
L2transfer & CEM & -10.833 & 3.706 & .015 & -19.970 & -1.697 \\
\hline
\end{tabular}

The next piece of data presents the analysis of translation test.

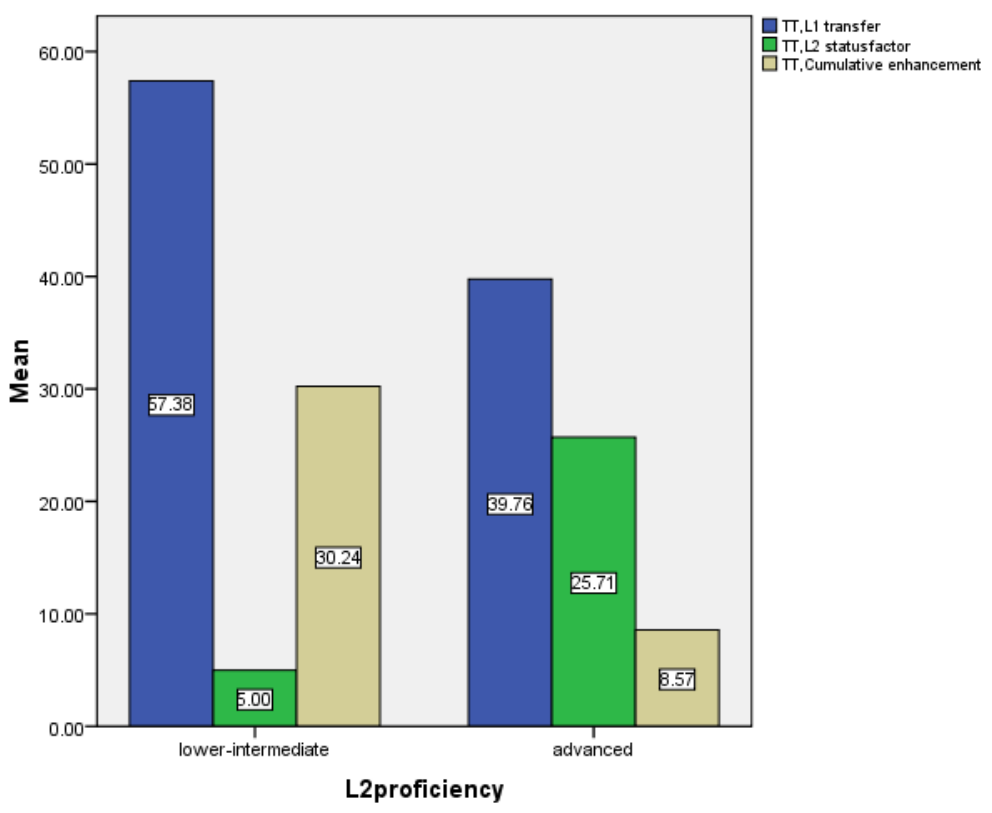

Figure 2. Participants' performance in TT

As one can inferred, in the first context the lower-intermediate outperformed the advanced learners. Nevertheless, the mean scores of the two groups were high in this context and it could be inferred that both groups transferred the Wh-question structures from L1 to L3.

In the second context (i.e., L2 status factor), the mean score of the advanced group was higher than that of the lower-intermediates. Although the advanced learners tended to transfer their L2 knowledge, their mean score was low compared to L1 transfer context. In this regard, the total mean score in this context was not very large compared to the first context. Finally, in the third context (i.e., CEM), the lower-intermediate group got the higher mean score than the advanced level. Nevertheless, the total mean score of this context was large compared to the second context (i.e., L2 status factor). Therefore, it could be realized that they partially transferred the features of L1 and L2 in L3. However, as the results of conducting two-way ANOVA showed, the differences in the participants' performance across levels of language proficiency were found statistically meaningful: 
Table 14. Mixed ANOVA results of TT

\begin{tabular}{|c|c|c|c|c|c|c|}
\hline Effect & value & $\mathrm{F}$ & $\begin{array}{l}\text { Hypothesis } \\
\text { df }\end{array}$ & $\begin{array}{l}\text { Error } \\
\mathrm{df}\end{array}$ & Sig. & $\begin{array}{l}\text { Partial Eta } \\
\text { squared }\end{array}$ \\
\hline Pillai's Trace & .732 & $77.905^{\mathrm{a}}$ & 2.00 & 57.00 & .000 & .732 \\
\hline Wilks' Lambda & .268 & $77.905^{\mathrm{a}}$ & 2.00 & 57.00 & .000 & .732 \\
\hline pillai's trace & .699 & 65.119 & 2.00 & 57.00 & .000 & .696 \\
\hline L2 PROF wilks' lambda & .304 & 65.119 & 2.00 & 57.00 & .000 & .696 \\
\hline
\end{tabular}

As it can be observed, the impact of the three contexts was significant. The pairwise comparison table showed where this difference lied. Additionally, the result showed that there was an interaction effect between the two groups with the contexts [wilks' Lambada $=0.30 \mathrm{~F}(2,57) 65.11, p=0.000]$. The partial eta squared was 0.69 showing a large effect size .Therefore, the performance of the students with the two different levels significantly differed in the three contexts. In this regard a one way repeated measure ANOVA was conducted to see where this difference lied. So the result of pairwise comparison of contexts of each group showed that the L1 was the main source of transfer.

Table 15. Pairwise comparison of contexts

\begin{tabular}{lllllll}
\hline (I) & $(\mathrm{J})$ & & & \multicolumn{2}{c}{$95 \%$ confidence interval for Difference ${ }^{\mathrm{a}}$} \\
\cline { 6 - 7 } context & context & Mean difference(I-J) & Std. Error & Sig. & Lower Bound & Upper bound $^{\text {L }}$ \\
\hline L1 transfer & L2transfer & 33.214 & 2.694 & .000 & 26.572 & 39.857 \\
L1transfer & CEM & 29.167 & 2.680 & .000 & 22.560 & 35.773 \\
L2transfer & CEM & --4.048 & 1.923 & .119 & -8.788 & .693 \\
\hline
\end{tabular}

\section{Discussion}

According to the first research question that is in line with testing L1 transfer hypothesis, the TT results showed that the mean scores of both groups were large compared to the other contexts. Additionally, in GJT the lower-intermediate group outperformed the advanced group in L1 transfer context. However, the advanced learners outperformed in L2 status factor but there was not a significant difference between L1 transfer and L2 status factor contexts. In general, in both tests the total mean score of L1 transfer context was large compared to the other contexts. Therefore, it can be concluded that the first research question is supported and the learners transfer the properties of wh-question structures from their native language (Persian) to L3. These findings are in line with the findings of Hakanssson et al. (2002), Garcia-Mayo (2012), (Leung, 2005 a \& b), Jin (2009), and Hermas $(2010,2014)$ who were the proponents of L1 transfer at the initial stage of L3 acquisition.

The second research question of this study dealt with L2 status factor and asserted that L2 is the main source of transfer in the L3 acquisition. Although the advanced learners outperformed the lower intermediates in this context in GJT, the obtained results of TT and GJT showed that the mean score of this context was low compared to the other contexts. Therefore, there is no evidence in support of L2status factor. These findings are different from the findings of Bardel \& Falk (2007, 2010), Leung (2005), Rothman \& Amaro (2010) and Galbat (2014) who claimed that L2 was the main source of transfer in the L3 acquisition.

The third research question investigated whether CEM can fully account for the results or not. In fact, proponents of CEM believe that that the transfer is selective and comes from all previous knowledge, either from L1 or L2. CEM supports the positive transfer, and assumes that there is a cumulative effect behind multilingualism, either there is an aid from previously learnt languages or there is no transfer at all and this effect remains neutral. The obtained results of TT and GJT showed that the lower-intermediates outperformed the advanced learners. However, the mean score of this context was large and the learners transferred the knowledge of both L1 and L2 into L3. Thus, the third research question is supported. These findings are in line with the findings of Flynn (2004) Leung (2005), and Berkes \& Flynn (2012).

Finally, the fourth research question dealt with the account of optimality theory for interrogative. Concerning the role of transfer, the following constraint hierarchies were obtained for TT and GJT. Q-Scope>> Lex-V $>$ Stay $>>$ Q-Mark and Stay $>>$ Lex-V $>>$ Q-Mark $>>$ Q-Scope. Regarding the L2 proficiency level, it can be assumed that the different performance of both groups in selecting the different types of French wh-questions can be accounted by optimality theory precisely. In other words, the lower-intermediate and advanced learners showed a different preference for the specific ranking of constraints in the acquisition of French simple 
wh-questions. The results showed that the lower-intermediate learners had better performance in L1transfer and CEM contexts. So they preferred the following rank of constraints in French wh-questions. The first ranking (a) shows that of CEM context, and the second one (b) shows that of L1 transfer one.

a) STAY $>$ LEX-V $>$ Q-MARK $>$ Q-SCOPE

b) Q-Scope $>$ Lex-V $>$ Stay $>$ Q-Mark

Furthermore, the obtained results of TT and GJT showed that the advanced learners were inclined to use the properties of L1 and L2 in the French Wh-question acquisition process. What follows are the ranking of constraints in the advanced group.

a) Q-SCOP $>$ Q-MARK $>$ LEXICAL-MOVEMENT $>$ LEXICAL-VERB $>$ STAY

b) Q-SCOPE $>$ LEX-VERB $>$ STAY $>$ Q-MARK

c) $\mathrm{Q}-\mathrm{MARK}>\mathrm{OP}-\mathrm{SPEC}>\mathrm{STAY}>\mathrm{LEX}-\mathrm{VERB}$

\section{Conclusion}

According to the results of TT and GJT, the two scenarios of transfer namely, L1 transfer hypothesis and CEM were confirmed. Concerning L2 proficiency the two groups of lower-intermediate and advanced learners had a significant difference in each context. Among the two proficiency levels, the advanced learners outperformed in L1 transfer context in TT and they outperformed in L2 status factor context in GJT. In general, both L1 transfer and L2 transfer contexts affected their performance in the acquisition process. Therefore, the English wh-question structure (i.e., wh movement with movement I to C) triggers the advanced learners to focus on this parallel structure in both L2 and L3 in their comprehension ability. Also, the Persian wh-question structure (i.e., wh-fronting without movement of I to C) triggers them to use this parallel structure in L1 and L3. Furthermore, the lower intermediates outperformed the advanced learners in contexts L1 transfer and CEM. Thus, the Persian (L1) wh-question structures (i.e., wh-fronting without movement of I to C) trigger the participants to take into account this parallel structure in the acquisition of French Wh-questions. Additionally, the properties of Persian and English structures (Wh- equo question) trigger the learners to utilize this parallel structure in the L3acquisition process.

\section{Acknowledgments}

Praise to almighty GOD for granting me the capability to proceed and complete this study. The present thesis would not have been possible without the guidance and support of numerous people. First and foremost, I would like to acknowledge my gratitude to my supervisor, Dr. Jabbari, for his patience, comments and encouragements throughout the work. I would also like to express my appreciation to my advisor, Dr. Rezaie, for his tolerance and practical advices. I am also grateful to all my professors at Yazd University. Last but not the least; I would like to thank my family for their endless love and supports.

\section{References}

Ackema, P., \& Neeleman, A. (1998). Optimal questions. Natural Language \& Linguistic Theory, 16(3), 443-490. http://dx.doi.org/10.1023/A:1006020702441

Aronin, L., \& Hufeisen, B. (2009). The Exploration of Multilingualism. Amsterdam: John Benjamins. http://dx.doi.org/10.1075/aals.6

Bardel, C., \& Falk, Y. (2007). The role of the second language in third language acquisition: The case of Germanic syntax. Second Language Research, 23(4), 459-484. http://dx.doi.org/10.1177/0267658307080557

Bardel, C., \& Falk, Y. (2010). Object pronouns in German L3 syntax: Evidence for the L2 status factor. Second Language Research, 27(1), 59-82.

Berkes, É., \& Flynn, S. (2012). Enhanced L3 Ln Acquisition and its Implications for Language Teaching. Cross-linguistic influences in multilingual language acquisition (pp. 1-22). Berlin: Springer Berlin Heidelberg. http://dx.doi.org/10.1007/978-3-642-29557-7_1

Falk, Y., \& Bardel, C. (2010). The study of the role of the background languages in third language acquisition. The state of the art. IRAL-International Review of Applied Linguistics in Language Teaching, 48(2-3), 185-219. http://dx.doi.org/10.1515/iral.2010.009

Flynn, S. (2009). UG and L3 acquisition: New insights and more questions. Third Language Acquisition and Universal Grammar, 71-89.

Flynn, S., Foley, C., \& Vinnitskaya, I. (2004). The cumulative-enhancement model for language acquisition: 
Comparing adults' and children's patterns of development in first, second and third language acquisition of relative clauses. International Journal of Multilingualism, 1(1), 3-16. http://dx.doi.org/10.1080/14790710408668175

Grimshaw, J. (1995). Projection, Heads, and Optimality. Ms., Rutgers University, New Brunswick, N.J. [ROA 68]. August, 2006.

Grimshaw, J. (1997). Projection, heads, and optimality. Linguistic Inquiry, 373-422.

Grosjean, F. (1989). Neurologists, beware! The bilingual is not two monolinguals in one person. Brain and Language, 36, 3-15. http://dx.doi.org/10.1016/0093-934X(89)90048-5

Hakansson, G., Pienemann, M., \& Sayheli, S. (2002). Transfer and typological proximity in the context of second language processing. Second Language Research, 18(33), 250-273. http://dx.doi.org/10.1191/0267658302sr206oa

Herdina, P., \& Jessner, U. (2002). A dynamic model of multilingualism: Perspectives of Change in Psycholinguistics, 121. Clevendon: Multilingual Matters.

Jessner, U. (1999). Metalinguistic awareness in multilinguals: Cognitive aspects of third language learning. Language Awareness, 8(3\&4), 201-209. http://dx.doi.org/10.1080/09658419908667129

Kager, R. (1999). Surface opacity of metrical structure in Optimality Theory. The Derivational Residue in Phonological Optimality Theory, 28, 207.

Kahnemuyipour, A. (2001). On wh-Questions in Persian. Canadian Journal of Linguistics, 46, 41-61.

Karimi, S. (2003). Focus movement and uninterpretable features. Formal Approaches to Function in Grammar: In Honor of Eloise Jelinek, 297-306. http://dx.doi.org/10.1075/la.62.21 kar

Leung, Y. K. I. (2005). L2 vs. L3 initial state: A comparative study of the acquisition of French DPs by Vietnamese monolinguals and Cantonese-English bilinguals. Bilingualism: Language and Cognition, 8, 39-61. http://dx.doi.org/10.1017/S1366728904002044

Lotfi, A. R. (2001). Iconicity: A generative perspective. Retrieved from http://www.geocities.com.arlotfi/lotfipage.htm

McCarthy, J. (2008). Doing Optimality Theory. Oxford: Blackwell Publishing Ltd. http://dx.doi.org/10.1002/9781444301182

Prince, A., \& Smolensky, P. (2004). Optimality Theory: Constraint interaction in generative grammar. Oxford: Blackwell Publishing Ltd. http://dx.doi.org/10.1002/9780470756171.ch1

Radford, A. (1997). Syntactic theory and the structure of English: A minimalist approach. Cambridge: Cambridge University Press. http://dx.doi.org/10.1017/cbo9781139166706

\section{Copyrights}

Copyright for this article is retained by the author(s), with first publication rights granted to the journal.

This is an open-access article distributed under the terms and conditions of the Creative Commons Attribution license (http://creativecommons.org/licenses/by/4.0/). 